\title{
An Update on Less Invasive and Endoscopic Techniques Mimicking the Effect of Bariatric Surgery
}

\author{
Froukje J. Verdam, ${ }^{1}$ Ruben Schouten, ${ }^{2}$ Jan Willem Greve, ${ }^{3}$ Ger H. Koek, ${ }^{4}$ and Nicole D. Bouvy ${ }^{1}$ \\ ${ }^{1}$ Department of General Surgery, Maastricht University Medical Centre, P.O. Box 5800, 6202 AZ Maastricht, The Netherlands \\ ${ }^{2}$ Department of Surgery, Bariatric Centre Lievensberg Hospital, P.O. Box 135, 4600 AC Bergen op Zoom, The Netherlands \\ ${ }^{3}$ Department of General Surgery, Atrium Medical Parkstad Centre, 6401 CX Heerlen, The Netherlands \\ ${ }^{4}$ Department of Gastroenterology, Maastricht University Medical Centre, P.O. Box 5800, 6202 AZ Maastricht, The Netherlands \\ Correspondence should be addressed to Nicole D. Bouvy, n.bouvy@mumc.nl
}

Received 20 January 2012; Revised 2 April 2012; Accepted 30 April 2012

Academic Editor: Bernhard Breier

Copyright ( $\odot 2012$ Froukje J. Verdam et al. This is an open access article distributed under the Creative Commons Attribution License, which permits unrestricted use, distribution, and reproduction in any medium, provided the original work is properly cited.

\begin{abstract}
Obesity (BMI $30-35 \mathrm{~kg} / \mathrm{m}^{2}$ ) and its associated disorders such as type 2 diabetes, nonalcoholic fatty liver disease, and cardiovascular disease have reached pandemic proportions worldwide. For the morbidly obese population (BMI $35-50 \mathrm{~kg} / \mathrm{m}^{2}$ ), bariatric surgery has proven to be the most effective treatment to achieve significant and sustained weight loss, with concomitant positive effects on the metabolic syndrome. However, only a minor percentage of eligible candidates are treated by means of bariatric surgery. In addition, the expanding obesity epidemic consists mostly of relatively less obese patients who are not (yet) eligible for bariatric surgery. Hence, less invasive techniques and devices are rapidly being developed. These novel entities mimic several aspects of bariatric surgery either by gastric restriction (gastric balloons, gastric plication), by influencing gastric function (gastric botulinum injections, gastric pacing, and vagal nerve stimulation), or by partial exclusion of the small intestine (duodenal-jejunal sleeve). In the last decade, several novel less invasive techniques have been introduced and some have been abandoned again. The aim of this paper is to discuss the safety, efficacy, complications, reversibility, and long-term results of these latest developments in the treatment of obesity.
\end{abstract}

\section{Background}

In the current era of obesity, research focuses on developing minimally invasive therapies to achieve effective and longlasting weight loss. For the severely obese population, noninvasive treatment (e.g., lifestyle modifications, pharmacological and behavioral therapy) shows modest and rarely durable effects. In contrast, bariatric surgery induces an indisputable, well-documented, sustained weight loss [1-5] and increases quality of life and life expectancy $[2,6,7]$. Over the last two decades, positive effects on type 2 diabetes mellitus (T2DM) $[8,9]$, nonalcoholic fatty liver disease (NAFLD) [10-12], cardiovascular disease $[13,14]$, and lipid profile $[15,16]$ are also acknowledged. Furthermore, indication criteria are expanding; whereas previously only patients with a BMI > $40 \mathrm{~kg} / \mathrm{m}^{2}$ or a BMI $>35 \mathrm{~kg} / \mathrm{m}^{2}$ complicated by obesityrelated comorbidities were eligible for bariatric surgery, diabetic subjects with a BMI between 30 and $35 \mathrm{~kg} / \mathrm{m}^{2}$ are currently also treated in trial context [17-19]. The overall complication rate of bariatric procedures is considered to be relatively low. Nonetheless, gastric banding is associated with slippage, erosion, ulcers, and pouch dilatation, while after malabsorptive surgery, dumping, anastomotic disruption and leakage, and long-term nutritional deficiencies are notorious complications [20-25]. Both the proven efficacy of bariatric surgery and the continuing emerging epidemic of obesity have induced an increase in the number of performed bariatric procedures [26]. However, still only a small percentage of the eligible severely obese candidates undergo bariatric surgery [27]. In addition, whereas severely obese patients are eligible for bariatric surgery, the obesity epidemic mostly concerns relatively less obese patients with or without comorbidity, who do not meet the current bodyweight criteria for surgical therapy. 
This encourages the development of less invasive techniques and devices mimicking the effects of conventional bariatric surgery on weight and comorbidities. However, it is pivotal to thoroughly evaluate the effects, safety, long-term results, and reversibility of these mainly endoscopic techniques before clinical implementation. Since many of these novel techniques have not been investigated in randomized settings, the aim of this paper is to provide an overview of the latest minimally invasive techniques mimicking conventional bariatric procedures. Both in surgical procedures and less invasive endoluminal techniques, it is important to make a clear distinction between gastric restrictive techniques and those based upon small intestinal exclusion. This paper summarizes techniques based upon gastric restriction, influencing gastric function, and techniques bypassing a part of the small intestine. The history and procedure is shortly explained and the efficacy on weight, comorbidity and encountered complications are discussed. Table 1 provides an overview of the types of procedures, concomitant sedation, the number of treated subjects so far, and their BMI range as well as the reported efficacy and complications.

Illustrations of both the gastric restrictive techniques and those based upon small intestinal exclusion are provided in Table 2.

\section{Gastric Techniques}

2.1. Intragastric Balloons. One of the first available endoscopic gastric restrictive techniques was the placement of an intragastric balloon. The gastric balloon, aiming to restrict gastric volume and enhance satiety, is a temporary device placed endoscopically under conscious sedation. Whereas in the 1980s, balloons were air-filled polyurethane pouches with sharp ridges $[28,29]$, currently available balloons are smooth, spherical, saline-filled or air-filled silicone devices (e.g., BioEnterics intragastric balloon, BIB, Allergan, Irvine, CA, USA; Heliosphere balloon, Heliosphere BAG, Heliscopie, Vienne, France), and some even allow for volume adjustments (Spatz Adjustable Balloon System, ABS, Jericho, NY, USA) [30]. When reviewing the literature, it is important to take both the development of balloons and the length of treatment into account [31]. Since the gastric balloon is a temporary device, the main concern is weight regain after removal. Therefore, some authors recommend using balloons only as a bridge to surgery $[32,33]$. There is a large heterogeneity with respect to both clinical and methodological aspects in clinical trials [34]. The duration of balloon treatment varies from 3 to 6 months [30,35], and BMI at implantation ranges from 27 to $60 \mathrm{~kg} / \mathrm{m}^{2}[36,37]$. Two randomized, double-blind, placebo-controlled trials $[32,38]$ and reviews $[34,39,40]$ have been published. Balloon treatment usually lasts for 6 months, inducing an average weight loss of $15 \mathrm{~kg}$ (range $9-21 \mathrm{~kg}$ ) or $34 \%$ EWL [26]. In a 12 month trial, an average weight loss of $24 \mathrm{~kg}$ was accomplished [30]. However, $15 \%$ of balloon treated subjects showed no or insufficient weight loss, and early balloon removal was reported in 3$7 \%$ of cases [32, 40,41]. Other complications are intolerance (e.g., dyspepsia, persistent emesis, ulcer, and esophagitis), spontaneous deflation, and a risk of distal migration and subsequent bowel obstruction [34, 41-44]. Gastric perforations have been reported but are exceptional [30, 35, 38, 45].

With respect to the risk of weight regain after removal, $28-80 \%$ of patients have regained their lost weight after one year [33]. The average remaining weight loss is $9 \mathrm{~kg}$ or $27 \%$ EWL, representing $10 \%$ of the total weight loss [46]. Two years after removal, $>10 \%$ EWL is maintained by $47 \%$ of patients [32], while $>15 \%$ EWL is maintained by $33-38 \%$ $[32,33]$. Dastis et al. showed an EWL of $>10 \%$ in $24 \%$ of patients after 2.5 years, while an average of $12.6 \% \mathrm{EWL}$ is achieved after 4.8 years [47].

Data on the effect on comorbidity are relatively scarce, although improved T2DM and hypertension in $87 \%$ and $94 \%$ of 1,394 patients has been reported [26]. Moreover, the positive effect of the gastric balloon on diabetes remains up to a year after balloon removal in about one third of the diabetic population [48]. In conclusion, even though the procedure of placement and retrieval of intragastric balloons proves to be relatively straightforward, one out of six patients is intolerant to the gastric balloon. Long-term data after balloon removal are scarce but show a modest weight reducing effect and amelioration of comorbidity in a minority of patients.

2.2. Transoral/Endoscopic Gastric Stapling. Similar to the formerly widely performed vertical gastric plication, endoscopic stapling procedures aim to create a restrictive gastric pouch. Endoluminal gastric stapling was first performed in 2007 and various locations, techniques, and devices have been used since (e.g., Eagle Claw, Olympus, Tokyo, Japan; USGI Medical, San Clemente, CA, USA; EndoCinch, CR Bard Inc., Murray Hill, NJ, USA; SurgASSIST, Power Medical Interventions Inc., New Hope, PA, USA; The Transoral Endoscopically Guided Stapling system, TOGA, Satiety Inc., Palo Alto, CA, USA; BaroSense Articulating Circular Endoscopic Stapler, ACE, Menlo Park, CA, USA). Primarily tested in rats, gastric plication of the anterior wall was found to induce less weight loss than plication of the greater curvature [49]. This is similar to findings in humans; depending on the location of the plication, $23 \%$ to $53 \%$ EWL has been reported in prospective, uncontrolled trials $[50,51]$.

Complications after gastric stapling consist of pain, nausea, and vomiting [51, 52]. Reoperations have been reported three times (once in a study of 15 patients, and two case reports), due to intractable vomiting, total dysphagia, or total gastric obstruction $[50,53,54]$. Moreover, there is no consensus yet on the optimal material to perform gastric plication. While a combination of staple-based fasteners and sutures failed, T-tags and buttressed T-tags were found to be durable for a period of 8 weeks in dogs [55]. However, it remains pivotal to investigate long-term durability of these materials.

The development of durable stapling methods and material is therefore a current focus in research; techniques are introduced, adjusted, and sometimes abandoned. For instance, the transoral endoscopic restrictive system (TERIS, BaroSense, Redwood, CA, USA) is a relatively new technique combining staples with a prosthesis at the level of the cardia. The TERIS created restriction by means of five silicone 


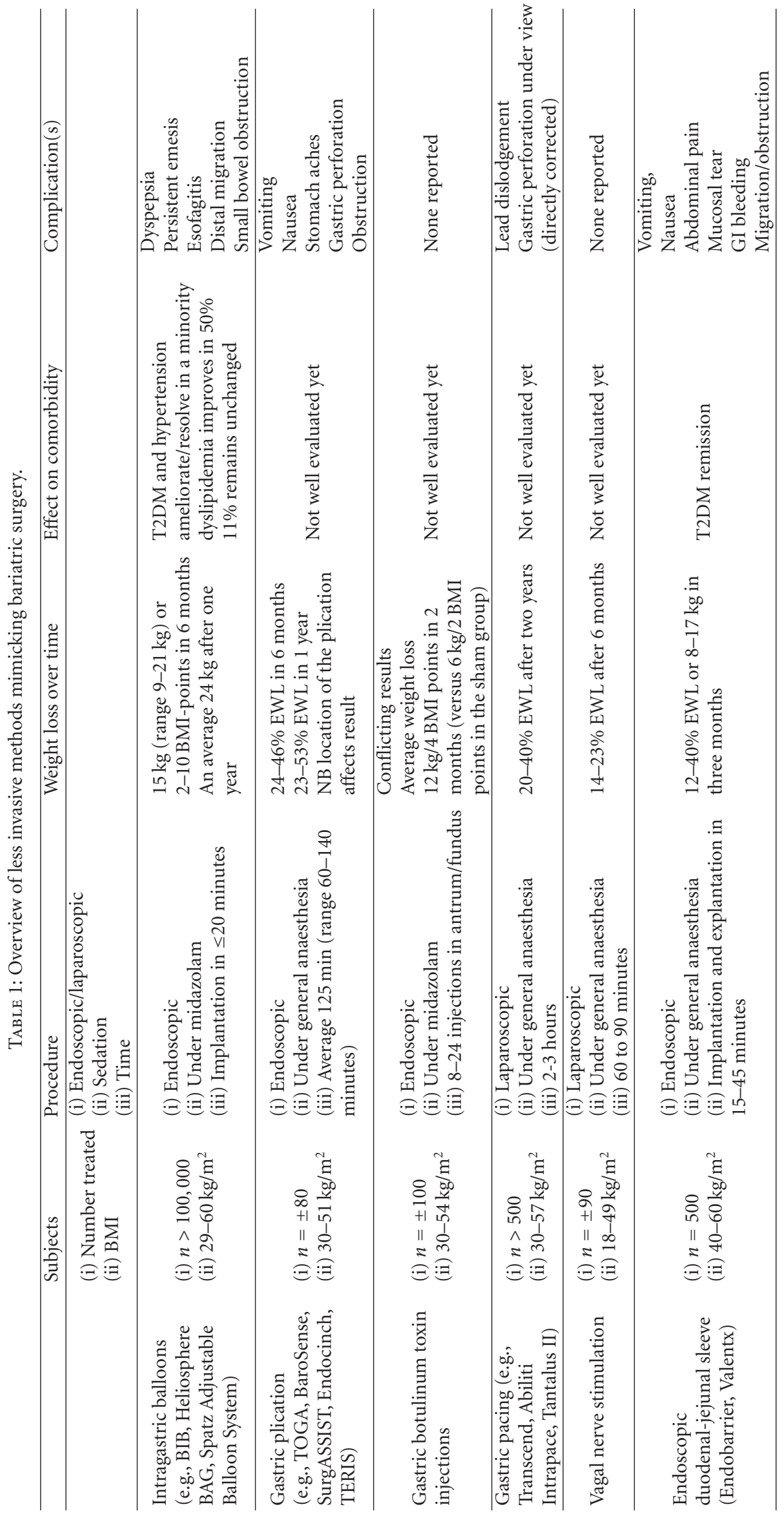


TABLE 2: Illustrations of methods mimicking bariatric surgery.

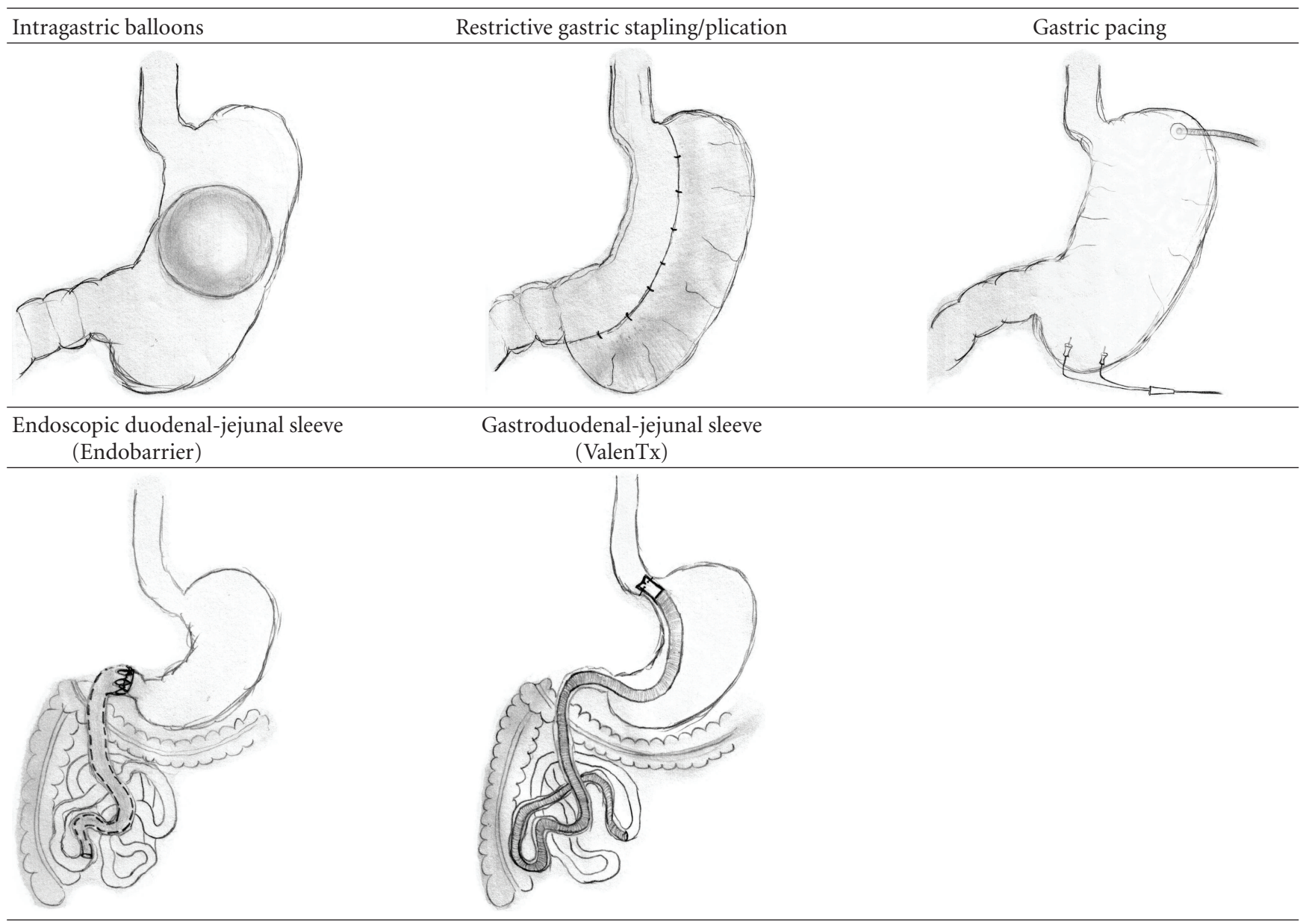

anchors placed through full-thickness, transmural plications in the cardia, just below the gastroesophageal junction, leaving a $10 \mathrm{~mm}$ restricting orifice in the middle $[51,56]$. A median EWL of $28 \%$ after three months was reported [ 57 , 58], but two cases developed a pneumoperitoneum requiring percutaneous intervention, and a third case suffered a gastric perforation with bleeding treated by laparoscopy $[57,58]$. A total complication rate of $25 \%$ resulted in withdrawal and necessary adjustments are awaited.

Another novel development aiming for relatively longer sustainability is the Expandable Tissue Anchor (USGI Medical Incorporated, San Clemente, CA, USA) consisting of two rated polyester expandable anchors with nitinol springs that are joined together over a polyester suture through the stomach wall. These expandable anchors distribute force over a much larger surface area than staples or sutures alone, although they have not been tested in a randomized setting yet [59]. In conclusion, gastric plication should only be performed in supervised clinical trials, and research on longterm sustainability of used materials is warranted.

\section{Techniques Potentially Influencing Gastric Function}

3.1. Gastric Botulinum Toxin Injection. Botulinum toxins are potent neuromuscular toxins produced by the anaerobic
Gram-positive Clostridium botulinum bacterium, primarily used in the management of muscular and glandular overactivity [60]. Botulinum toxin blocks the release of acetylcholine from the neuron by preventing the vesicles in which acetylcholine is stored from binding to the membrane where they release their content [61]. In the 1950s, injecting overactive muscles with minute quantities of botulinum toxin type A was found to decrease muscle activity for a period of three to four months [62]. Injecting botulinum toxin type A in the gastric wall was first discovered to induce weight loss in both normal-weight $[63,64]$ and obese rats [65]. In humans, endoscopic injections with gastric botulinum toxin has led to conflicting results, potentially due to differences in the location of administration (antrum and/or fundus region), doses of the toxin, and patient selection [66].

Most studies show no effect of botulinum toxin injections in the antrum alone [67-69], or similar effects as observed in controls who underwent saline injections [64]. In contrast, injections in both fundus and antrum seem to be more effective $[67,68]$. With respect to the different doses of toxin, conflicting results are published. Some report no differences between groups injected with various doses of botulinum toxin $[64,70-72]$, whereas others show a reduction of gastric emptying time and gastric volume only with a relatively high dose of 300 units $[67,73]$. One of the most positive 
randomized, double-blind studies showed twice as much weight loss in botulinum toxin treated patients than in saline injected controls after 2 months $(12 \mathrm{~kg}$ or $4 \mathrm{BMI}$ points versus $6 \mathrm{~kg}$ or $2 \mathrm{BMI}$ points) [68]. Concomitant increased satiety together with a reduced gastric emptying time, gastric capacity and alterations in levels of satiety regulating hormones (ghrelin and peptide YY) have also been described [69]. Complications were not reported in any of the studies. To our knowledge, effects on comorbidity have not been evaluated yet.

In summary, none of the studies have a longer followup than four months and overall results are disappointing. Therefore, the potential effect on weight of botulinum injections and overall effectiveness remains disputable. Botulinum injections do not offer a permanent solution for obesity.

3.2. Gastric Pacing. Laparoscopic implantable gastric stimulation (gastric pacing) is a technique generating electrical pulses via bipolar leads along the lesser curvature. These leads are placed into the seromuscular layer of the gastric wall under general anesthesia, and connected to a generator which is positioned subcutaneously along the abdominal wall. Electrical stimulation, which was primarily used as a therapy for gastroparesis unresponsive to medical treatment, can be performed by gastric electrical pacing, high-frequency gastric electrical stimulation, and sequential neural electrical stimulation [74]. Variations of continuous, intermittent, short-pulse width and high frequency or long-pulse width and low frequency can be supplied. This technique does not rely on gastric restriction or intestinal malabsorption, but induces early satiety as was first observed by a diminished food intake in pigs [75]. A confirmative study in dogs showed a reduction in parasympathetic activity and a diminished inhibition of gastric myoelectrical activity [76]. In rats, short-pulse gastric electrical stimulation led to a fourfold increase in vagal activity, whereas this effect was abolished after vagotomy or capsaicin administration [77]. Various devices have been used for application in human obesity, such as the Transcend Implantable Gastric Stimulator (Transneuronix Inc. and Enterra Therapy system, Medtronic, Minneapolis, MN, USA), the Intrapace Abiliti Gastric Stimulator (Menlo Park, CA, USA), and the Diamond/Tantalus II system (Metacure, Kfar-Saba, Israel). The Transcend device, providing continuous gastric wall stimulation, was retrieved by Medtronic in December 2005 due to a lack of efficacy, potentially due to habituation. More recent devices such as the Abiliti and Tantalus provide gastric electric stimulation on demand following food intake, thereby enhancing the antral contraction amplitude and inducing premature satiety $[78,79]$.

The first results in obese patients showed that gastric pacing induces reduced appetite and enhanced satiety [80, 81]. Nonrandomized trials with a follow-up time between 10 to 24 months reported $20-40 \%$ EWL in a total of 500 severely obese patients $\left(\mathrm{BMI}>40 \mathrm{~kg} / \mathrm{m}^{2}\right)$ [78, 80, 82-86]. Less obese patients with a BMI range of $30-35 \mathrm{~kg} / \mathrm{m}^{2}$ showed 6\% EWL after 6 months [87], while diabetic patients also showed positive results $[79,84,88]$. More specifically, 49 of a total of 61 diabetic patients in two studies showed an average reduction of $1 \%$ in $\mathrm{HbA}_{1 \mathrm{c}}$. However, the most important but less encouraging results derive from two prospective, randomized, placebo-controlled, double-blind trials; the O01 trial and Screened Health Assessment and Pacer Evaluation (SHAPE) trial [89]. Twelve percent EWL after one year was reported in both treated and control groups. Some patients had lost significant weight, while others showed little or no response. In order to predict positive outcome, an algorithm based on baseline age, gender, body weight, $\mathrm{BMI}$, and responses to a preoperative questionnaire, was developed. By means of this algorithm it was found that only $18-33 \%$ of the originally included population would benefit from gastric pacing with $>30 \%$ EWL in 12-29 months [90].

Importantly, reported complications are partial or complete dislodgment of the leads in a minority of cases, and more seldom, perforations of the stomach during lead implantation, which can be managed directly. In short, gastric pacing is an interesting technique, but optimal stimulation patterns, the underlying mechanism(s), and the effect on comorbidity are to be elucidated. There is insufficient scientific evidence to support gastric pacing as a suitable treatment for obesity.

3.3. Vagal Nerve Stimulation. Vagal nerve stimulation (VNS) is performed by subcutaneous positioning of an electrode pulsing to the vagus nerve (e.g., EnteroMedics VBLOC, St. Paul, MN, USA). This technique was first indicated in epilepsy [91] and severe, therapy-resistant depression [92]. Vagal pacing showed to diminish food intake, fat mass, and weight in pigs [93], rats [94], and obese minipigs [95], suggesting that VNS induces satiety signals. Body weight was found to be reduced mainly at the expense of body fat, whereas metabolic rate remained unaffected [96]. Depressed patients undergoing VNS were also reported to have less sweet cravings [97] and to lose weight [95, 98]. However, discussion remains on both the ideal positioning of the electrode and the frequency of the blocking algorithm. For example, the electrode can be placed at the trunk of the left vagal nerve midway between the clavicle and the mastoid [98], or at both vagal nerves near the esophagogastric junction [99]. In the context of different blocking algorithms, a positive relation between the number of 90-150-s algorithms delivered daily and weight loss has been reported [99], but comparative studies have not been performed. In addition, it is difficult to compare the outcome of various studies because weight loss is not reported in a similar manner. An average reduction of 14-23\% EWL after 6 months of VNS has been reported $(n=53)$, whereas others found an average weight loss of two BMI points or seven $\mathrm{kg}$ after one year [98]. No serious adverse events have been encountered. Nonetheless, it is ambiguous whether or not VNS can induce a definite sustainable therapeutic effect on obesity. Its potential clinical value has to be confirmed in randomized controlled trials.

\section{Partial Exclusion of the Small Intestine}

4.1. The Endoluminal Duodenal-Jejunal Sleeve. Two available endoluminal devices mimic the effect of exclusion of the 
proximal intestine, thereby simulating a proximal small intestinal bypass without changes in anatomy. The first device on the market was the Endobarrier (GI dynamics Inc., Lexington, MA, USA). This $60 \mathrm{~cm}$ single use impermeable fluoropolymer sleeve is endoscopically delivered into the duodenal bulb, where it holds itself in place by a selfexpanding nickel-titanium alloy (Nitinol) anchor. The sleeve stretches out into the duodenum and the first part of the jejunum; therefore chyme passes through the interior while pancreatic and biliary juices pass alongside the exterior of the sleeve [100]. In trials, implantation and removal mostly took place under general anesthesia, on average within 1545 minutes [101-104], but these procedures are also possible under conscious sedation. The device has first been tested in pigs $[105,106]$ and thereafter in both nonrandomized [26] and randomized clinical trials with diet control groups, with and without sham endoscopy $[103,104]$. After three months, a mean EWL of $12-19 \%$ in device subjects was reported, versus 3-7\% EWL in the control group on a diet [103, 104]. Most complications, such as abdominal pain, nausea, and vomiting, were transient and encountered during the first week after implantation [101-104]. However, in a total of over 500 implantations with a maximum duration of implantation of one year, more serious adverse events were also encountered. These events were hematemesis (3 in a study of 21 patients) [26], controllable gastrointestinal bleeding [26], sleeve migration ( 4 out of 52 patients in two studies) [103, 107], obstruction (1 out of 30) [103], and two mucosal tears (an oropharyngeal and an oesofageal mucosal tear) [101]. All complications were managed conservatively, endoscopically, or by retrieval of the device. Moreover, they have led to technical adjustments of the self-expanding anchor.

Importantly, consistent positive effects on satiety and comorbidity such as T2DM, hypertension, and hyperlipidemia are reported [101-104, 107]. Sustainable reductions in fasting blood glucose, insulin, and $\mathrm{HbA}_{1 \mathrm{c}}(-2.1 \pm 0.3 \%)$ were observed. Whereas one out of 22 patients had an $\mathrm{HbA}_{1 \mathrm{c}}<7 \%$ at baseline, 16 out of 22 patients had an $\mathrm{HbA}_{1 \mathrm{c}}<7 \%$ after one year of treatment [107]. Therefore, this device, primarily used as a bridge to surgery for the severely obese population, is now also considered as a device to treat otherwise therapy resistant obesity-induced T2DM. Long-term follow-up data after removal are however not yet available.

The second device, the ValenTx (ValenTx Inc, Carpinteria, CA, USA), is another implantable and removable sleeve launched in 2011 and placed by a combination of endoscopy and laparoscopy [108]. This device is twice as long as the Endobarrier $(120 \mathrm{~cm}$ versus $60 \mathrm{~cm})$, and also bypasses the stomach. Whereas the Endobarrier is characterized by a self-expanding anchor in the duodenum, the ValenTx is laparoscopically attached to the distal esophagus. During the procedure, the gastroesophageal junction is dissected at the level of the diaphragmatic hiatus and a polyester cuff is placed by eight full-thickness suture anchors. The only published three-month trial showed that 17 out of 22 implanted patients (77\%) maintained the device, reaching an average of $40 \%$ EWL. Improvement of glycemic status was achieved in all 7 diabetic patients. After three months, the
17 sleeves that remained in situ varied with respect to their length left in the stomach. Of the total 120 centimeters, 10 to 40 centimeters was found to reside in the stomach, whereas the remainder was left in the duodenum and proximal jejunum. Up to date, this device is removed after three months and long-term follow-up data as well as data after removal are yet to be investigated.

\section{Discussion}

The battle against the obesity epidemic has given rise to many new interdisciplinary developments and an increasingly important role for the endoscopist. For severe obesity, conventional bariatric surgery is considered to be the only effective and best studied therapy. However, the current era also demands effective therapies for the relatively moderate obese population. In addition, partially due to capacity and costs, only a small percentage of the eligible candidates undergo bariatric surgery. Therefore, novel less invasive treatment options are a focus in research and every day clinic. The need for effective minimal invasive treatments will continue to increase, but a sound critical attitude towards these novel techniques should be maintained before they can become an inherent part of clinical practice. As previously stated by the expert panel on weight loss surgery, the golden standard to investigate the safety and efficacy of interventions for the treatment of obesity and its complications should be by means of randomized, blinded, sham-controlled clinical trials [109]. Even though sham-controlled trials cannot always be executed due to medical ethical considerations, it remains pivotal not to focus only on a (temporary) effect on weight and/or comorbidity and potential complications. Careful consideration should also be given to investigating the underlying mechanism together with long-term followup of treated subjects, before these techniques are regarded as accepted therapies for obesity and its comorbidity. This paper aimed to provide an overview of recently developed relatively minimal invasive techniques. Some techniques have been or will be retracted, some will be relaunched, and some will turn out to be successful in only a specific part of the obese population. Even though short-term results of some of the recently developed techniques and devices are promising, it is important to consider them as experimental until convincing evidence is published.

\section{Abbreviations}

ABS: Adjustable balloon system

ACE: Articulating circular endoscopic stapler

BMI: Body mass index

BIB: BioEnterics intragastric balloon

EWL: Excess weight loss

NAFLD: Nonalcoholic fatty liver disease

SHAPE: Screened Health Assessment and Pacer Evaluation

T2DM: Diabetes type 2

TOGA: Transoral gastroplasty

TERIS: Transoral endoscopic restrictive system

VNS: Vagal nerve stimulation. 


\section{References}

[1] H. Buchwald, "Management of morbid obesity: surgical options," The Journal of Family Practice, pp. S10-S17, 2005.

[2] H. Buchwald, R. Estok, K. Fahrbach, D. Banel, and I. Sledge, "Trends in mortality in bariatric surgery: a systematic review and meta-analysis," Surgery, vol. 142, no. 4, pp. 621-635, 2007.

[3] M. Neovius, K. Johansson, and S. Rössner, "Head-to-head studies evaluating efficacy of pharmaco-therapy for obesity: a systematic review and meta-analysis," Obesity Reviews, vol. 9, no. 5, pp. 420-427, 2008.

[4] L. Sjostrom, Kristina Narbro, C. Sjöström et al., "Effects of bariatric surgery on mortality in Swedish obese subjects," The New England Journal of Medicine, vol. 357, no. 8, pp. 741-752, 2007.

[5] D. J. Tessier and J. C. Eagon, "Surgical management of morbid obesity," Current Problems in Surgery, vol. 45, no. 2, pp. 68-137, 2008.

[6] R. Padwal, S. Klarenbach, N. Wiebe et al., "Bariatric surgery: a systematic review and network meta-analysis of randomized trials," Obesity Reviews, vol. 12, no. 8, pp. 602-621, 2011.

[7] A. E. Pontiroli and A. Morabito, "Long-term prevention of mortality in morbid obesity through bariatric surgery. A systematic review and meta-analysis of trials performed with gastric banding and gastric bypass," Annals of Surgery, vol. 253, no. 3, pp. 484-487, 2011.

[8] H. Buchwald, R. Estok, K. Fahrbach et al., "Weight and type 2 diabetes after bariatric surgery: systematic review and metaanalysis," American Journal of Medicine, vol. 122, no. 3, pp. 248.e5-256.e5, 2009.

[9] P. C. Sala, R. S. Torrinhas, S. B. Heymsfield et al., "Type 2 diabetes mellitus: a possible surgically reversible intestinal dysfunction," Obesity Surgery, vol. 22, no. 1, pp. 167-176, 2012.

[10] R. R. Mummadi, K. S. Kasturi, S. Chennareddygari, and G. K. Sood, "Effect of bariatric surgery on nonalcoholic fatty liver disease: systematic review and meta-analysis," Clinical Gastroenterology and Hepatology, vol. 6, no. 12, pp. 13961402, 2008.

[11] A. R. de Andrade, H. P. Cotrim, E. Alves et al., "Nonalcoholic fatty liver disease in severely obese individuals: the influence of bariatric surgery," Annals of Hepatology, vol. 7, no. 4, pp. 364-368, 2008.

[12] C. M. Tai, C. K. Huang, J. C. Hwang et al., "Improvement of nonalcoholic fatty liver disease after bariatric surgery in morbidly obese Chinese patients," Obesity Surgery. In press.

[13] V. G. Athyros, K. Tziomalos, A. Karagiannis, and D. P. Mikhailidis, "Cardiovascular benefits of bariatric surgery in morbidly obese patients," Obesity Reviews, vol. 12, no. 7, pp. 515-524, 2011.

[14] Y. Wang and C. Zhang, "Bariatric surgery to correct morbid obesity also ameliorates atherosclerosis in patients with type 2 diabetes mellitus," American Journal of Biomedical Sciences, vol. 1, no. 1, pp. 56-69, 2009.

[15] I. Garcia-Marirrodriga, "Evolution of lipid profiles after bariatric surgery," Obesity Surgery, vol. 22, no. 4, pp. 609-616, 2012.

[16] R. E. Brolin, L. J. Bradley, A. C. Wilson, and R. P. Cody, "Lipid risk profile and weight stability after gastric restrictive operations for morbid obesity," Journal of Gastrointestinal Surgery, vol. 4, no. 5, pp. 464-469, 2000.

[17] J. B. Dixon, P. Zimmet, K. G. Alberti, and F. Rubino, "Bariatric surgery: an IDF statement for obese Type 2 diabetes," Surgery for Obesity and Related Diseases, vol. 7, no. 4, pp. 433-447, 2011.

[18] C. E. Reis, "Role of bariatric-metabolic surgery in the treatment of obese type 2 diabetes with body mass index < $35 \mathrm{~kg} / \mathrm{m}(2)$ : a literature review," Diabetes Technology and Therapeutics, vol. 14, no. 4, pp. 365-372, 2012.

[19] M. Gianos, "Outcomes of bariatric surgery in patients with body mass index $<35 \mathrm{~kg} / \mathrm{m} 2$," Surgery for Obesity and Related Diseases, vol. 8, no. 1, pp. 25-30, 2012.

[20] O. Ziegler, M. A. Sirveaux, L. Brunaud, N. Reibel, and D. Quilliot, "Medical follow up after bariatric surgery: nutritional and drug issues General recommendations for the prevention and treatment of nutritional deficiencies," Diabetes and Metabolism, vol. 35, no. 6, pp. 544-557, 2009.

[21] A. E. Chapman, G. Kiroff, P. Game et al., "Laparoscopic adjustable gastric banding in the treatment of obesity: a systematic literature review," Surgery, vol. 135, no. 3, pp. 326351, 2004.

[22] C. Doherty, J. W. Maher, and D. S. Heitshusen, "Prospective investigation of complications, reoperations, and sustained weight loss with an adjustable gastric banding device for treatment of morbid obesity," Journal of Gastrointestinal Surgery, vol. 2, no. 1, pp. 102-108, 1998.

[23] M. J. Monteforte and C. M. Turkelson, "Bariatric surgery for morbid obesity," Obesity Surgery, vol. 10, no. 5, pp. 391-401, 2000.

[24] J. A. Tice, L. Karliner, J. Walsh, A. J. Petersen, and M. D. Feldman, "Gastric banding or bypass? A systematic review comparing the two most popular bariatric procedures," American Journal of Medicine, vol. 121, no. 10, pp. 885-893, 2008.

[25] B. M. Balsiger, M. M. Murr, J. L. Poggio, and M. G. Sarr, "Bariatric surgery: surgery for weight control in patients with morbid obesity," Medical Clinics of North America, vol. 84, no. 2, pp. 477-489, 2000.

[26] G. P. Kohn, J. A. Galanko, D. W. Overby, and T. M. Farrell, "Recent trends in bariatric surgery case volume in the United States," Surgery, vol. 146, no. 2, pp. 375-380, 2009.

[27] K. A. Elder and B. M. Wolfe, "Bariatric surgery: a review of procedures and outcomes," Gastroenterology, vol. 132, no. 6, pp. 2253-2271, 2007.

[28] R. B. Hogan, J. H. Johnston, B. W. Long et al., "A doubleblind, randomized, sham-controlled trial of the gastric bubble for obesity," Gastrointestinal Endoscopy, vol. 35, no. 5, pp. 381-385, 1989.

[29] M. Schapiro, S. Benjamin, G. Blackburn et al., "Obesity and the gastric balloon: a comprehensive workshop. Tarpon Springs, Florida, March 19-21," Gastrointestinal Endoscopy, vol. 33, no. 4, pp. 323-327, 1987.

[30] E. Machytka, P. Klvana, A. Kornbluth et al., "Adjustable intragastric balloons: a 12-month pilot trial in endoscopic weight loss management," Obesity Surgery, vol. 21, no. 10, pp. 1499-1507, 2011.

[31] E. Espinet-Coll, J. Nebreda-Durán, J. A. Gómez-Valero et al., "Current endoscopic techniques in the treatment of obesity," Revista Espanola de Enfermedades Digestivas, vol. 104, no. 2, pp. 72-87, 2012.

[32] E. M. H. Mathus-Vliegen and G. N. J. Tytgat, "Intragastric balloon for treatment-resistant obesity: safety, tolerance, and efficacy of 1-year balloon treatment followed by a 1-year balloon-free follow-up," Gastrointestinal Endoscopy, vol. 61, no. 1, pp. 19-27, 2005.

[33] M. Saruç, D. Böler, M. Karaarslan et al., "Intragastric balloon treatment of obesity must be combined with bariatric 
surgery: a pilot study in Turkey," Turkish Journal of Gastroenterology, vol. 21, no. 4, pp. 333-337, 2010.

[34] M. Fernandes, A. N. Atallah, B. G. Soares et al., "Intragastric balloon for obesity," Cochrane Database of Systematic Reviews, vol. 1, Article ID CD004931, 2007.

[35] E. Totté, L. Hendrickx, M. Pauwels, and R. Van Hee, "Weight reduction by means of intragastric device: experience with the bioenterics intragastric balloon," Obesity Surgery, vol. 11, no. 4, pp. 519-523, 2001.

[36] S. Roman, B. Napoléon, F. Mion et al., "Intragastric balloon for "non-morbid" obesity: a retrospective evaluation of tolerance and efficacy," Obesity Surgery, vol. 14, no. 4, pp. 539544, 2004.

[37] L. Busetto, G. Segato, M. De Luca et al., "Preoperative weight loss by intragastric balloon in super-obese patients treated with laparoscopic gastric banding: a case-control study," Obesity Surgery, vol. 14, no. 5, pp. 671-676, 2004.

[38] A. Genco, T. Bruni, S. B. Doldi et al., "BioEnterics intragastric balloon: the Italian experience with 2,515 patients," Obesity Surgery, vol. 15, no. 8, pp. 1161-1164, 2005.

[39] J. M. Dumonceau, "Evidence-based review of the bioenterics intragastric balloon for weight loss," Obesity Surgery, vol. 18, no. 12, pp. 1611-1617, 2008.

[40] E. M. H. Mathus-Vliegen, "Intragastric balloon treatment for obesity: what does it really offer?" Digestive Diseases, vol. 26, no. 1, pp. 40-44, 2007.

[41] I. Imaz, C. Martínez-Cervell, E. E. García-Álvarez, J. M. Sendra-Gutiérrez, and J. González-Enríquez, "Safety and effectiveness of the intragastric balloon for obesity. A metaanalysis," Obesity Surgery, vol. 18, no. 7, pp. 841-846, 2008.

[42] P. Trande, A. Mussetto, V. G. Mirante et al., "Efficacy, tolerance and safety of new intragastric air-filled balloon (Heliosphere BAG) for obesity: the experience of 17 cases," Obesity Surgery, vol. 20, no. 9, pp. 1227-1230, 2010.

[43] E. M. H. Mathus-Vliegen, "Obesity: intragastric balloonsa bubble to combat the obesity bubble?" Nature Reviews Gastroenterology and Hepatology, vol. 7, no. 1, pp. 7-8, 2010.

[44] N. Tsesmeli and D. Coumaros, "Review of endoscopic devices for weight reduction: old and new balloons and implantable prostheses," Endoscopy, vol. 41, no. 12, pp. 1082-1089, 2009.

[45] A. Al-Momen and I. El-Mogy, "Intragastric balloon for obesity: a retrospective evaluation of tolerance and efficacy," Obesity Surgery, vol. 15, no. 1, pp. 101-105, 2005.

[46] J. Herve, C. H. Wahlen, A. Schaeken et al., "What becomes of patients one year after the intragastric balloon has been removed?" Obesity Surgery, vol. 15, no. 6, pp. 864-870, 2005.

[47] N. S. Dastis, E. François, J. Deviere et al., "Intragastric balloon for weight loss: results in 100 individuals followed for at least 2.5 years," Endoscopy, vol. 41, no. 7, pp. 575-580, 2009.

[48] N. Crea, G. Pata, D. Della Casa et al., "Improvement of metabolic syndrome following intragastric balloon: 1 year followup analysis," Obesity Surgery, vol. 19, no. 8, pp. 1084-1088, 2009.

[49] P. E. B. Fusco, R. S. Poggetti, R. N. Younes, B. Fontes, and D. Birolini, "Comparison of anterior gastric wall and greater gastric curvature invaginations for weight loss in rats," Obesity Surgery, vol. 17, no. 10, pp. 1340-1345, 2007.

[50] S. A. Brethauer, J. L. Harris, M. Kroh, and P. R. Schauer, "Laparoscopic gastric plication for treatment of severe obesity," Surgery for Obesity and Related Diseases, vol. 7, no. 1, pp. 15-22, 2011.

[51] J. Deviere, G. Ojeda Valdes, L. Cuevas Herrera et al., "Safety, feasibility and weight loss after transoral gastroplasty: first human multicenter study," Surgical Endoscopy, vol. 22, no. 3, pp. 589-598, 2008.

[52] J. Pujol Gebelli, A. García Ruiz de Gordejuela, A. Casajoana Badía, L. Secanella Medayo, A. Vicens Morton, and C. Masdevall Noguera, "Laparoscopic Gastric Plication: a new surgery for the treatment of morbid obesity," Cirugia Espanola, vol. 89, no. 6, pp. 356-361, 2011.

[53] B. M. Watkins, "Gastric compartment syndrome: anunusual complication of gastric plication surgery," Surgery for Obesity and Related Diseases. In press.

[54] A. Tsang and V. Jain, "Pitfalls of bariatrictourism: a complication of gastric plication," Surgery for Obesity and Related Diseases. In press.

[55] H. J. Menchaca, J. L. Harris, S. E. Thompson, M. Mootoo, V. N. Michalek, and H. Buchwald, "Gastric plication: preclinical study of durability of serosa-to-serosa apposition," Surgery for Obesity and Related Diseases, vol. 7, no. 1, pp. 8-14, 2011.

[56] C. Moreno, J. Closset, S. Dugardeyn et al., "Transoral gastroplasty is safe, feasible, and induces significant weight loss in morbidly obese patients: results of the second human pilot study," Endoscopy, vol. 40, no. 5, pp. 406-413, 2008.

[57] K. de Jong, E. M. H. Mathus-Vliegen, E. A. M. L. Veldhuyzen, J. H. Eshuis, and P. Fockens, "Short-term safety and efficacy of the Trans-oral Endoscopic Restrictive Implant System for the treatment of obesity," Gastrointestinal Endoscopy, vol. 72, no. 3, pp. 497-504, 2010.

[58] L. Biertho, F. S. Hould, S. Lebel, and S. Biron, "Transoral endoscopic restrictive implant system: a new endoscopic technique for the treatment of obesity," Surgery for Obesity and Related Diseases, vol. 6, no. 2, pp. 203-205, 2010.

[59] S. G. Brengman M, P. M. Denk, and L. L. Swanstrom, "Durability of endoscopically placed suturs utilized for bariatric and non-bariatric applications," Oral presentation IFSO, 2010.

[60] J. N. Panicker and U. B. Muthane, "Botulinum toxins: pharmacology and its current therapeutic evidence for use," Neurology India, vol. 51, no. 4, pp. 455-460, 2003.

[61] A. S. Burgen, F. Dickens, and L. J. Zatman, "The action of botulinum toxin on the neuro-muscular junction," The Journal of Physiology, vol. 109, no. 1-2, pp. 10-24, 1949.

[62] G. E. Borodic, R. Ferrante, L. B. Pearce, and K. Smith, "Histologic assessment of dose-related diffusion and muscle fiber response after therapeutic botulinum A toxin injections," Movement Disorders, vol. 9, no. 1, pp. 31-39, 1994.

[63] D. García-Compean, E. Mendoza-Fuerte, J. A. Martínez, I. Villarreal, and H. Maldonado, "Endoscopic injection of botulinum toxin in the gastric antrum for the treatment of obesity: results of a pilot study," Gastroenterologie Clinique et Biologique, vol. 29, no. 8-9, pp. 789-791, 2005.

[64] R. Mittermair, C. Keller, and J. Geibel, "Intragastric injection of botulinum toxin A for the treatment of obesity," Obesity Surgery, vol. 17, no. 6, pp. 732-736, 2007.

[65] H. Coskun, Y. Duran, E. Dilege, M. Mihmanli, H. Seymen, and M. O. Demirkol, "Effect on gastric emptying and weight reduction of botulinum toxin-A injection into the gastric antral layer: an experimental study in the obese rat model," Obesity Surgery, vol. 15, no. 8, pp. 1137-1143, 2005.

[66] D. Garcia-Compean and H. M. Garza, "Intragastric injection of botulinum toxin for the treatment of obesity. Where are we?" World Journal of Gastroenterology, vol. 14, no. 12, pp. 1805-1809, 2008.

[67] D. Foschi, F. Corsi, M. Lazzaroni et al., "Treatment of morbid obesity by intraparietogastric administration of botulinum 
toxin: a randomized, double-blind, controlled study," International Journal of Obesity, vol. 31, no. 4, pp. 707-712, 2007.

[68] D. Foschi, M. Lazzaroni, O. Sangaletti, F. Corsi, E. Trabucchi, and G. Bianchi Porro, "Effects of intramural administration of Botulinum Toxin A on gastric emptying and eating capacity in obese patients," Digestive and Liver Disease, vol. 40, no. 8, pp. 667-672, 2008.

[69] L. Li, Q. S. Liu, W. H. Liu et al., "Treatment of obesity byendoscopic gastric intramural injection of botulinum toxin A: a randomized clinical trial," Hepato-Gastroenterology. In press.

[70] G. Albani, M. L. Petroni, A. Mauro et al., "Safety and efficacy of therapy with botulinum toxin in obesity: a pilot study," Journal of Gastroenterology, vol. 40, no. 8, pp. 833-835, 2005.

[71] A. C. Júnior, P. R. Savassi-Rocha, L. G. Vaz Coelho et al., "Botulinum A toxin injected into the gastric wall for the treatment of class III obesity: a pilot study," Obesity Surgery, vol. 16, no. 3, pp. 335-343, 2006.

[72] D. Gui, G. Mingrone, V. Valenza et al., "Effect of botulinum toxin antral injection on gastric emptying and weight reduction in obese patients: a pilot study," Alimentary Pharmacology and Therapeutics, vol. 23, no. 5, pp. 675-680, 2006.

[73] M. Topazian, M. Camilleri, J. De La Mora-Levy et al., "Endoscopic ultrasound-guided gastric botulinum toxin injections in obese subjects: a pilot study," Obesity Surgery, vol. 18, no. 4, pp. 401-407, 2008.

[74] M. Bortolotti, "The "electrical way" to cure gastroparesis," American Journal of Gastroenterology, vol. 97, no. 8, pp. 18741883, 2002.

[75] V. V. Cigaina, A. Saggioro, V. Rigo, G. P. Pinato, and S. Ischia, "Long-term effects of gastric pacing to reduce feed intake in swine," Obesity Surgery, vol. 6, no. 3, pp. 250-253, 1996.

[76] H. Ouyang, J. Yin, and J. D. Z. Chen, "Therapeutic potential of gastric electrical stimulation for obesity and its possible mechanisms: a preliminary canine study," Digestive Diseases and Sciences, vol. 48, no. 4, pp. 698-705, 2003.

[77] J. Liu, X. Qiao, and J. D. Z. Chen, "Vagal afferent is involved in short-pulse gastric electrical stimulation in rats," Digestive Diseases and Sciences, vol. 49, no. 5, pp. 729-737, 2004.

[78] A. Bohdjalian, G. Prager, R. Aviv et al., "One-year experience with Tantalus: a new surgical approach to treat morbid obesity," Obesity Surgery, vol. 16, no. 5, pp. 627-634, 2006.

[79] S. Policker, W. Haddad, and I. Yaniv, "Treatment of type 2 diabetes using meal-triggered gastric electrical stimulation," Israel Medical Association Journal, vol. 11, no. 4, pp. 206-208, 2009.

[80] M. De Luca, G. Segato, L. Busetto et al., "Progress in implantable gastric stimulation: summary of results of the European multi-center study," Obesity Surgery, vol. 14, supplement 1, pp. S33-S39, 2004.

[81] V. Cigaina and A. L. Hirschberg, "Gastric pacing for morbid obesity: plasma levels of gastrointestinal peptides and leptin," Obesity Research, vol. 11, no. 12, pp. 1456-1462, 2003.

[82] F. Favretti, M. De Luca, G. Segato et al., "Treatment of morbid obesity with the Transcend implantable gastric stimulator (IGS): a prospective survey," Obesity Surgery, vol. 14, no. 5, pp. 666-670, 2004.

[83] K. Miller, E. Hoeller, and F. Aigner, "The implantable gastric stimulator for obesity: an update of the European experience in the LOSS (Laparoscopic Obesity Stimulation Survey) study," Treatments in Endocrinology, vol. 5, no. 1, pp. 53-58, 2006.
[84] V. Cigaina, "Long-term follow-up of gastric stimulation for obesity: the mestre 8-year experience," Obesity Surgery, vol. 14, supplement 1, pp. S14-S22, 2004.

[85] S. A. Shikora, "What are the yanks doing?' The U.S. experience with Implantable Gastric Stimulation (IGS) for the treatment of obesity - update on the ongoing clinical trials," Obesity Surgery, vol. 14, supplement 1, pp. S40-S48, 2004.

[86] J. D'Argent, "Gastric electrical stimulation as therapy of morbid obesity: preliminary results from the French study," Obesity Surgery, vol. 12, supplement 1, pp. 21S-25S, 2002.

[87] J. K. Champion, M. Williams, S. Champion, J. Gianos, and C. Carrasquilla, "Implantable gastric stimulation to achieve weight loss in patients with a low body mass index: early clinical trial results," Surgical Endoscopy and Other Interventional Techniques, vol. 20, no. 3, pp. 444-447, 2006.

[88] C. P. Sanmiguel, J. L. Conklin, S. A. Cunneen et al., "Gastric electrical stimulation with the TANTALUS System in obese type 2 diabetes patients: effect on weight and glycemic control," Journal of Diabetes Science and Technology, vol. 3, no. 4, pp. 964-970, 2009.

[89] S. A. Shikora, R. Bergenstal, M. Bessler et al., "Implantable gastric stimulation for the treatment of clinically severe obesity: results of the SHAPE trial," Surgery for Obesity and Related Diseases, vol. 5, no. 1, pp. 31-37, 2009.

[90] S. A. Shikora and K. Storch, "Implantable gastric stimulation for the treatment of severe obesity: the American experience," Surgery for Obesity and Related Diseases, vol. 1, no. 3, pp. 334342, 2005.

[91] J. G. Burneo, E. Faught, R. Knowlton, R. Morawetz, and R. Kuzniecky, "Weight loss associated with vagus nerve stimulation,” Neurology, vol. 59, no. 3, pp. 463-464, 2002.

[92] M. Kosel and T. E. Schlaepfer, "Mechanisms and state of the art of vagus nerve stimulation," Journal of ECT, vol. 18, no. 4, pp. 189-192, 2002.

[93] A. Matyja, P. J. Thor, J. Sobocki et al., "Effects of vagal pacing on food intake and body mass in pigs," Folia Medica Cracoviensia, vol. 45, no. 3-4, pp. 55-62, 2004.

[94] A. J. Bugajski, K. Gil, A. Ziomber, D. Zurowski, W. Zaraska, and P. J. Thor, "Effect of long-term vagal stimulation on food intake and body weight during diet induced obesity in rats," Journal of Physiology and Pharmacology, vol. 58, no. 1, pp. 512, 2007.

[95] D. Val-Laillet, A. Biraben, G. Randuineau, and C. H. Malbert, "Chronic vagus nerve stimulation decreased weight gain, food consumption and sweet craving in adult obese minipigs," Appetite, vol. 55, no. 2, pp. 245-252, 2010.

[96] J. Sobocki, G. Fourtanier, J. Estany, and P. Otal, "Does vagal nerve stimulation affect body composition and metabolism? Experimental study of a new potential technique in bariatric surgery," Surgery, vol. 139, no. 2, pp. 209-216, 2006.

[97] J. S. Bodenlos, S. Kose, J. J. Borckardt et al., "Vagus nerve stimulation acutely alters food craving in adults with depression," Appetite, vol. 48, no. 2, pp. 145-153, 2007.

[98] J. V. Pardo, S. A. Sheikh, M. A. Kuskowski et al., "Weight loss during chronic, cervical vagus nerve stimulation in depressed patients with obesity: an observation," International Journal of Obesity, vol. 31, no. 11, pp. 1756-1759, 2007.

[99] W. Richards, "Comment on: selection of electrical algorithms to treat obesity with intermittent vagal block using an implantable medical device," Surgery for Obesity and Related Diseases, vol. 5, no. 2, pp. 229-230, 2009.

[100] K. S. Gersin, J. E. Keller, D. Stefanidis et al., "DuodenalJejunal bypass sleeve: a totally endoscopic device for the 
treatment of morbid obesity," Surgical Innovation, vol. 14, no. 4, pp. 275-278, 2007.

[101] L. Rodriguez-Grunert, M. P. Galvao Neto, M. Alamo, A. C. Ramos, P. B. Baez, and M. Tarnoff, "First human experience with endoscopically delivered and retrieved duodenal-jejunal bypass sleeve," Surgery for Obesity and Related Diseases, vol. 4, no. 1, pp. 55-59, 2008.

[102] A. Escalona, R. Yáñez, and F. Pimentel, "Initial human experience with restrictive duodenal-jejunal bypass liner for treatment of morbid obesity," Surgery for Obesity and Related Diseases, vol. 6, no. 2, pp. 126-131, 2010.

[103] R. Schouten, C. S. Rijs, N. D. Bouvy et al., "A multicenter, randomized efficacy study of the endobarrier gastrointestinal liner for presurgical weight loss prior to bariatric surgery," Annals of Surgery, vol. 251, no. 2, pp. 236-243, 2010.

[104] K. S. Gersin, R. I. Rothstein, R. J. Rosenthal et al., "Openlabel, sham-controlled trial of an endoscopic duodenojejunal bypass liner for preoperative weight loss in bariatric surgery candidates," Gastrointestinal Endoscopy, vol. 71, no. 6, pp. 976-982, 2010.

[105] M. Tarnoff, S. Shikora, A. Lembo, and K. Gersin, "Chronic in-vivo experience with an endoscopically delivered and retrieved duodenal-jejunal bypass sleeve in a porcine model," Surgical Endoscopy and Other Interventional Techniques, vol. 22, no. 4, pp. 1023-1028, 2008.

[106] M. Tarnoff, S. Shikora, and A. Lembo, "Acute technical feasibility of an endoscopic duodenal-jejunal bypass sleeve in a porcine model: a potentially novel treatment for obesity and type 2 diabetes," Surgical Endoscopy and Other Interventional Techniques, vol. 22, no. 3, pp. 772-776, 2008.

[107] E.G. de Moura, B. C. Martins, G. S. Lopes et al., "Metabolic improvements in obese type 2 diabetes subjects implanted for 1 year with an endoscopically deployed duodenal-jejunal bypass liner," Diabetes Technology and Therapeutics, vol. 14, no. 2, pp. 183-189, 2012.

[108] B. J. Sandler, R. Rumbaut, C. P. Swain et al., "Human experience with an endoluminal, endoscopic, gastrojejunal bypass sleeve," Surgical Endoscopy, vol. 25, no. 9, pp. 3028-3033, 2011.

[109] G. L. lackburn, M. M. Hutter, A. M. Harvey et al., "Expert panel on weight loss surgery: executive report update," Obesity, vol. 17, no. 5, pp. 842-862, 2009. 


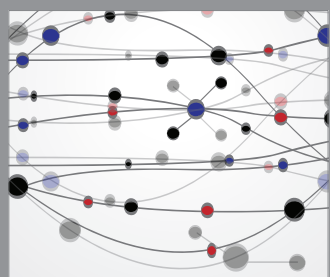

The Scientific World Journal
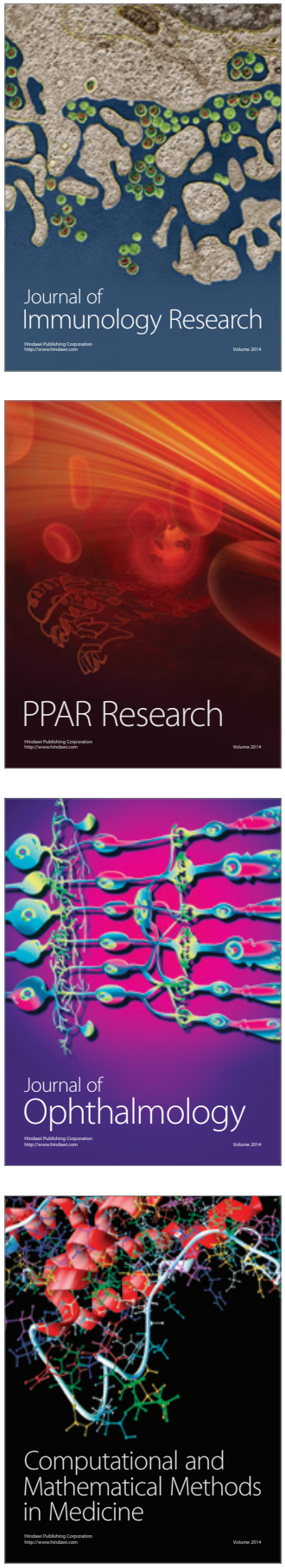

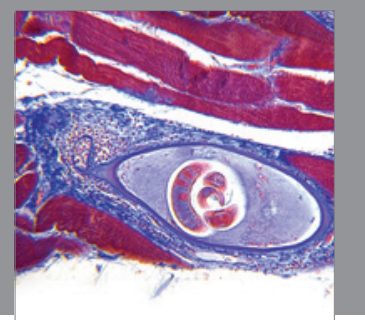

Gastroenterology

Research and Practice
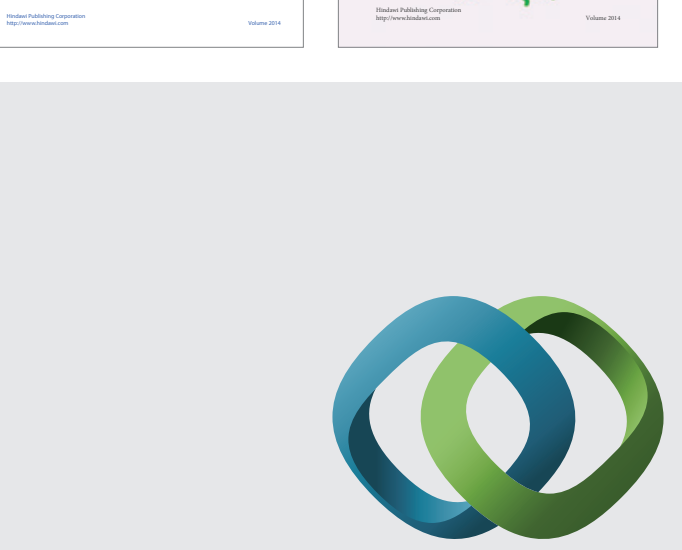

\section{Hindawi}

Submit your manuscripts at

http://www.hindawi.com
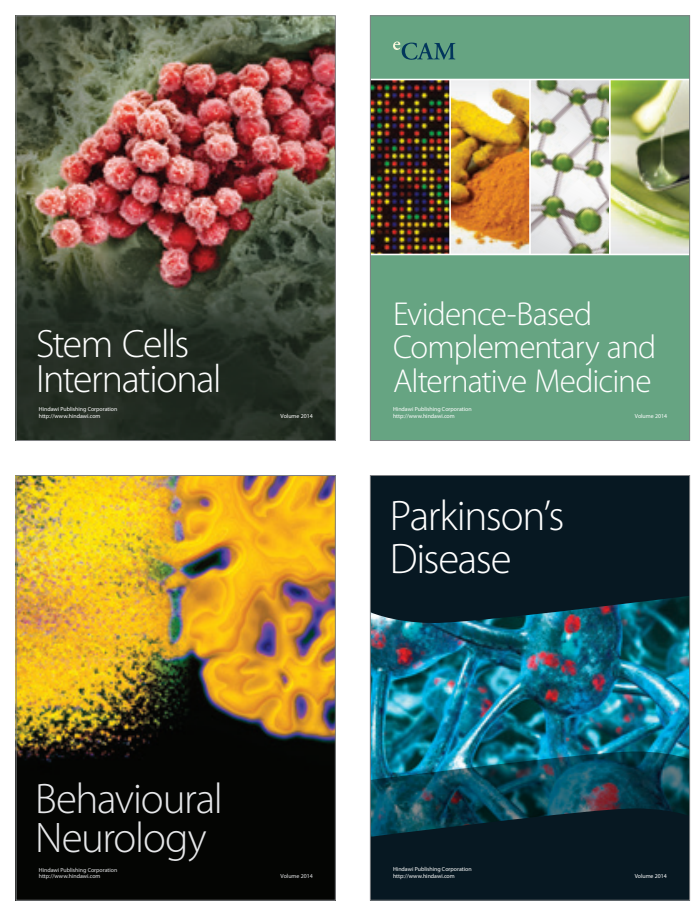

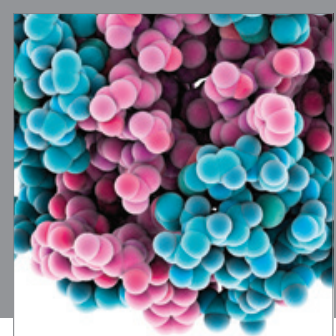

Journal of
Diabetes Research

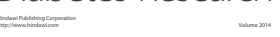

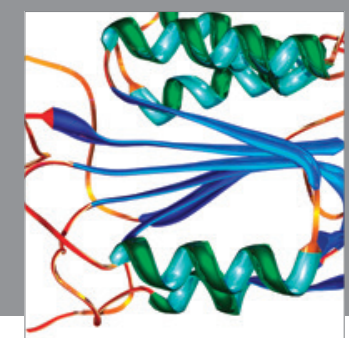

Disease Markers
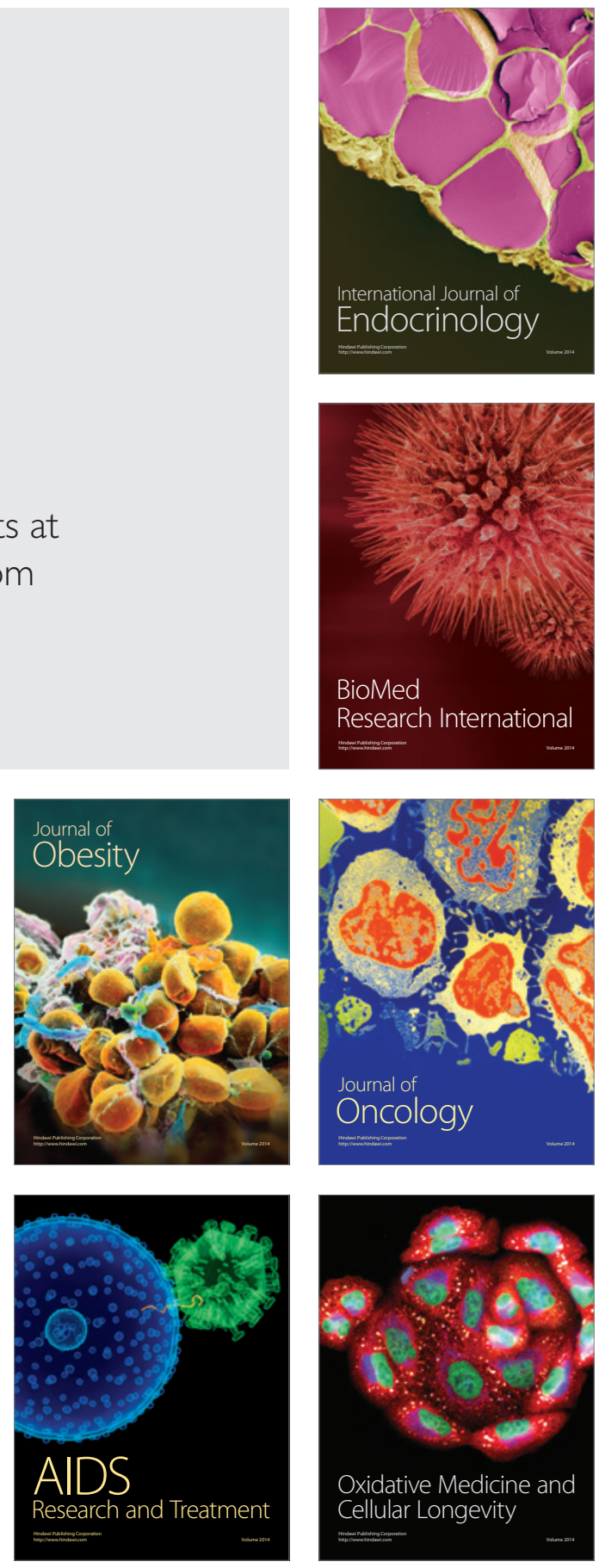